\title{
Reflectometer comparison for assessment of back-silvered glass solar mirrors
}

\author{
Christopher Sansom ${ }^{1, \text { a) }}$, Aránzazu Fernández-García ${ }^{2}$, Peter King ${ }^{1}$, \\ Florian Sutter ${ }^{3}$ and Alejandro Garcia Segura ${ }^{2}$ \\ ${ }^{1}$ Global CSP Laboratory, Cranfield University, Bedfordshire MK43 0AL, UK. \\ ${ }^{2}$ CIEMAT-Plataforma Solar de Almería, Senes Road, Km. 4.5, P.O. Box 22, E04200 Tabernas, Almería, Spain \\ ${ }^{3}$ DLR, Institute of Solar Research, PSA, Senes Road, Km. 4.5, P.O. Box 44, E04200 Tabernas, Almería, Spain
}

a) corresponding author $\underline{\text { c.l.sansom@ } @ \text { cranfield.ac.uk }}$

\begin{abstract}
This paper compares the two most common reflectometers used to assess the specular reflectance of back-silvered glass mirrors for Concentrating Solar Power (CSP) applications, namely the Device and Services (D\&S) 15R-USB and the Abengoa Condor SR-6.1 instruments. Comparisons are first made between the two instruments themselves using a Gage Repeatability and Reproducibility (R\&R) study. Results are given for the as-cleaned collector mirrors and then as the mirrors become naturally soiled over a one month period. The results of the Gage R\&R study show that for the D\&S the gage itself contributes $40.97 \%$ of the variability, whilst $59.03 \%$ is due to part-to-part (location on the mirror under investigation) variability. For the Condor we show that the \% Contribution from the gage is $62.18 \%$ of the total variability with only $37.82 \%$ of the contribution attributable to the location dependent reflectance. The Condor has a wider acceptance angle, and over the reflectance range of $0.91-0.95$ the condor was found to measure higher than the D\&S by an average of $1.53 \%$. The differences between the soiling results obtained from the two instruments are explained, and the results are used to derive a predictive model for the soiling of solar collectors. In conclusion, both instruments have advantages and shortcomings, and the factors that influence which instrument to select are discussed.
\end{abstract}

\section{Nomenclature}

$\begin{array}{ll}\text { Acronyms } & \\ \text { ANOVA } & \text { Analysis of Variance } \\ \text { CSP } & \text { Concentrating Solar Power } \\ \text { DNI } & \text { Direct Normal Irradiance } \\ \text { D\&S } & \text { Device \& Services } \\ \text { R\&R } & \text { Repeatability and Reproducibility } \\ \text { PSA } & \text { Plataforma Solar de Almería } \\ \text { OPAC } & \text { Optical Ageing Characterization (Laboratory) } \\ \text { PTC } & \text { parabolic-trough collector } \\ \text { LCL } & \text { Lower statistical Control Limit } \\ \text { UCL } & \text { Upper statistical Control Limit }\end{array}$

Symbols

$R \quad$ reflectance

$\Delta R \quad$ change in reflectance

$\sigma_{\text {total }}^{2}$

total variance in measurement of reflectance 


$\begin{array}{ll}\sigma^{2}{ }_{\text {refl }} & \text { variance in reflectance measurement attributable to the part } \\ \sigma^{2} \text { gage } & \text { variance in reflectance measurement attributable to the reflectometer } \\ \sigma^{2}{ }_{\text {repeatability }} & \text { variance in reflectance measurement attributable to instrument repeatability } \\ \sigma^{2} \text { reproducibility } & \text { variance in reflectance measurement attributable to observer (reproducibility) } \\ \text { Xbar } & \text { Facet average reflectance by location (on Minitab plots) } \\ \text { CI } & \text { Confidence Interval } \\ \text { DF } & \text { Degrees of freedom } \\ \text { P } & \text { Probability } \\ \text { R-Sq } & \text { Percentage of data described by the best-fit line } \\ \text { S } & \text { Standard deviation of how far the data values fall from the fitted values } \\ \text { SS } & \text { Sum of squares }\end{array}$

\section{Introduction}

The performance of CSP plants (both with parabolic-trough collectors - PTC- and solar towers) is critically dependent on the optical efficiency of the solar field, particularly the specular solar reflectance of the solar concentrating mirrors. Generally made of back-silvered glass of up to $4 \mathrm{~mm}$ thickness, the mirrors and their tracking and supporting structures are also a significant capital cost (Pitz-Paal et al., 2007). Alternative reflecting materials are available (Bethea et al., 1981; DiGrazia et al., 2009; Sutter et al, 2012) but their robustness and durability has yet to be proven. Reflectance loss occurs most frequently by natural soiling with dust and sand, which is especially severe in the arid regions where CSP plants are preferentially located for reasons of high Direct Normal Irradiance (DNI) (Fernández-García et al., 2014a). Specular solar reflectance measurements on large solar collectors require specialist equipment, including purpose-built reflectometers. These mainly include the Abengoa Condor SR-6.1 (Martínez et al., 2012; Salinas et al., 2016), the D\&S 15R-USB (Pettit, 1982; Ho et al., 2013), and the Surface Optics 410-Solar hand-held instrument (Crawford et al., 2012; Ho et al., 2013). The correct choice of instrument for on-field reflectance measurements must accomplish a set of requirements, comprising accuracy, high autonomy, easy to handle and operate, light weight, store system, with no influence from external light.

In this work a comparison is made between the two most commonly used reflectometers, namely the Abengoa Condor SR-6.1 and the D\&S 15R-USB instruments. Following a statistical analysis of both instruments in laboratory conditions using a Gage $R \& R$ technique, we carried out a field study with measurements taken as natural soiling occurs on a representative solar collector located outdoors at the CIEMAT-PSA, in the desert region of Tabernas in Andalucía, Spain. The quality of the results from this two reflectometers are of particular interest because they are the most frequently used in existing commercial CSP plants and are also widely employed in research activities for both soiling characterization (Tahboub et al., 2012; Bouaddi et al., 2015) and durability assessment (Fernández-García et al., 2014b).

\section{Methodology}

This section includes a description of the two instruments included in the present research study and the methodology followed both in the Gage R\&R study and in the soiling outdoor experiments. A Gage R\&R study provides a means to assess the origin of the variability seen in a set of measurements. This variability can be due to the difference between the sites being measured, but can also be due to the operator of the instrument or the performance of the instrument itself. A Gage R\&R study indicates 
whether the operators are consistent in their measurements of the same part (repeatability) and whether the variation between operators is consistent (reproducibility). Statistical software is a useful tool to perform this task, and for this work Minitab statistical software was selected.

\subsection{Instrument description}

The instruments under study are shown in Fig. 1, and their main features are listed in Table 1.
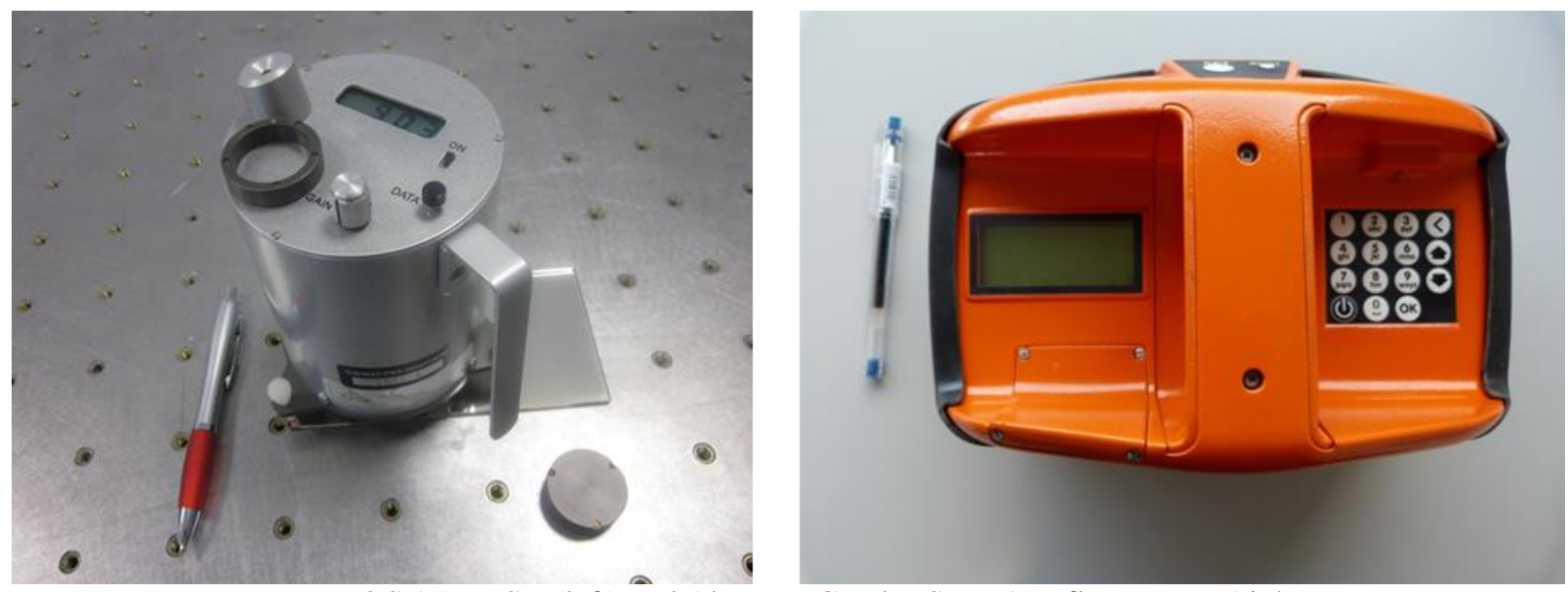

Fig 1. D\&S 15R-USB (left) and Abengoa Condor SR-6.1 reflectometer (right).

Table 1

Main features of the D\& S 15R-USB and Abengoa Condor SR-6.1 reflectometers (Fernández-García et al., 2017).

\begin{tabular}{|c|c|c|}
\hline Manufacturer & D\&S Co & Abengoa Solar New Technologies \\
\hline Model & $15 R$-USB & Condor SR-6.1 \\
\hline Measurement principle & $\begin{array}{c}\text { A source lamp and a detector positioned } \\
\text { in incidence and outgoing angles }\end{array}$ & $\begin{array}{c}\text { Six optical channels composed by a } \\
\text { source lamp and two detectors }\end{array}$ \\
\hline Measurement type & Specular reflectance at selected $\varphi$ & Specular reflectance \\
\hline Light source & LED & Six LED \\
\hline Incidence angle, $\theta_{i}\left({ }^{\circ}\right)$ & 15 & 12 \\
\hline Beam spot size (diameter in mm) & 10.00 & 1.00 \\
\hline Wavelength range, $\lambda(\mathrm{nm})$ & Peak at 660 & $435,525,650$, \\
\hline Acceptance angle, $\varphi$ (mrad) & $3.5,7.5,12.5,23.0$ & 204 \\
\hline Accuracy (reflectance units) & N/A & \pm 0.002 \\
\hline Repeatability (reflectance units) & \pm 0.002 & \pm 0.002 \\
\hline Resolution (reflectance units) & \pm 0.001 & \pm 0.001 \\
\hline Adaptable to mirror curvature & Yes & No \\
\hline $\begin{array}{c}\text { Suitable for } 1^{\text {st }} \text { and } 2^{\text {nd }} \text { surface } \\
\text { mirrors }\end{array}$ & Yes & Yes \\
\hline Influence of external light & No (chopped light source) & No (synchronous detection at \\
\hline
\end{tabular}




\begin{tabular}{|c|c|c|}
\hline & & modulated frequency) \\
\hline Weight $(\mathrm{kg})$ & 1.10 & 1.40 \\
\hline Operating temp. $\left({ }^{\circ} \mathrm{C}\right)$ & $0-50$ & $0-55$ \\
\hline Autonomy & $49-52 \mathrm{~h}$ & 1200 measurements \\
\hline
\end{tabular}

The Condor SR-6.1 Portable Reflectometer (named in the rest of this document as the Condor) was developed by Abengoa Solar New Technologies and the University of Zaragoza with a focus on usability and applications in operations and maintenance. Every measurement consists of six different beam sources of $435 \mathrm{~nm}, 525 \mathrm{~nm}, 650 \mathrm{~nm}, 780 \mathrm{~nm}, 940 \mathrm{~nm}$ and $1050 \mathrm{~nm}$. Although results were collected at all six wavelengths, only the $650 \mathrm{~nm}$ results are reported here so as to compare with the single wavelength measurements of the D\&S reflectometer. According to the manufacturer the Condor has a resolution of \pm 0.001 , a repeatability of \pm 0.002 reflectance units, with $95 \%$ confidence, and an accuracy of \pm 0.002 reflectance units. The (half) acceptance aperture is $204 \mathrm{mrad}$. There are different versions of the D\&S 15R-USB (named in the rest of this document as the D\&S), with both $550 \mathrm{~nm}$ and $660 \mathrm{~nm}$ sources, but always with acceptance apertures less that the Condor ( $23 \mathrm{mrad}, 12.5 \mathrm{mrad}, 7.5 \mathrm{mrad}$, or $3.5 \mathrm{mrad}$ ). The D\&S used in our experiments has a $660 \mathrm{~nm}$ source and the acceptance aperture selected was $12.5 \mathrm{mrad}$, that being the standard to study PTC technology (Meyen et al., 2010). According to the manufacturer the D\&S-15R has a resolution of \pm 0.001 and repeatability of \pm 0.002 reflectance units. Each reflectometer has its own calibration reference piece, therefore it is expected that the reflectance measured on each will differ slightly, even on the just-cleaned mirrors. Note also the difference in acceptance aperture between the two instruments. The Condor has a wider acceptance aperture in order to assess mirrors possessing a wider range of curvatures and thicknesses. The penalty for this is an overestimate in the measurement of reflectance, which has been estimated in previous work to be less than $1.35 \%$ (Salinas et al., 2016).

\subsection{Reflectometer Gage $R \& R$}

Any conclusions drawn from measurements made using either of the two reflectometers (the "gages") under investigation will depend on the accuracy of the data. If either the measuring instrument or the measurement method is not capable of making accurate or repeatable measurements, the data will contain an error. An analysis of the measurement system usually requires an investigation of repeatability, reproducibility, bias, stability, and linearity. In order to assess and compare the accuracy of reflectance measurements taken using the Condor and the D\&S instruments in the context of measuring solar glass mirror reflectance, it is necessary to measure their individual values of repeatability and reproducibility. The repeatability of each instrument is the closeness of the agreement between successive measurements when carried out under the same conditions. These conditions demand the same operator using the same instrument at the same location over a short period of time (to maintain steady room conditions). The dispersion of the results is a measure of repeatability. Reproducibility is the closeness of agreement between successive measurements when carried out over changed conditions. The changed condition is most often taken to mean a change in the operator, and that is the approach that is taken in our analysis. As before, the dispersion of the results is a measure of reproducibility. 
When measuring reflectance this can be expressed as in equation (1), where the total variance in the measurement, $\sigma^{2}$ total, is a function of the variance owing to the reflectance measurement itself, $\sigma^{2}$ refl, plus the variance due to the gage, $\sigma_{\text {gage }}^{2}$.

$$
\sigma_{\text {total }}^{2}=\sigma_{\text {refl }}^{2}+\sigma_{\text {gage }}^{2}
$$

where $\sigma_{\text {gage }}^{2}$ is expressed in equation (2).

$$
\sigma_{\text {gage }}^{2}=\sigma_{\text {repeatability }}^{2}+\sigma_{\text {reproducibility }}^{2}
$$

being $\sigma_{\text {repeatability }}^{2}$ and $\sigma^{2}$ reproducibility the variance due to the repeatability and reproducibility of the gage, respectively.

Reflectance measurements were taken in the OPAC laboratory at the PSA (a joint laboratory between Spanish research center CIEMAT and the German research center DLR) using both the Condor (from Cranfield University) and the D\&S (from OPAC laboratory) reflectometers. The sample or "part" measured was a $4 \mathrm{~mm}$ thick back-silvered solar mirror facet section (taken from a PTC) of length $1.7 \mathrm{~m}$ and width $0.3 \mathrm{~m}$. Three observers took measurements at five approximately equidistant points on the mirror as shown in Fig 2.
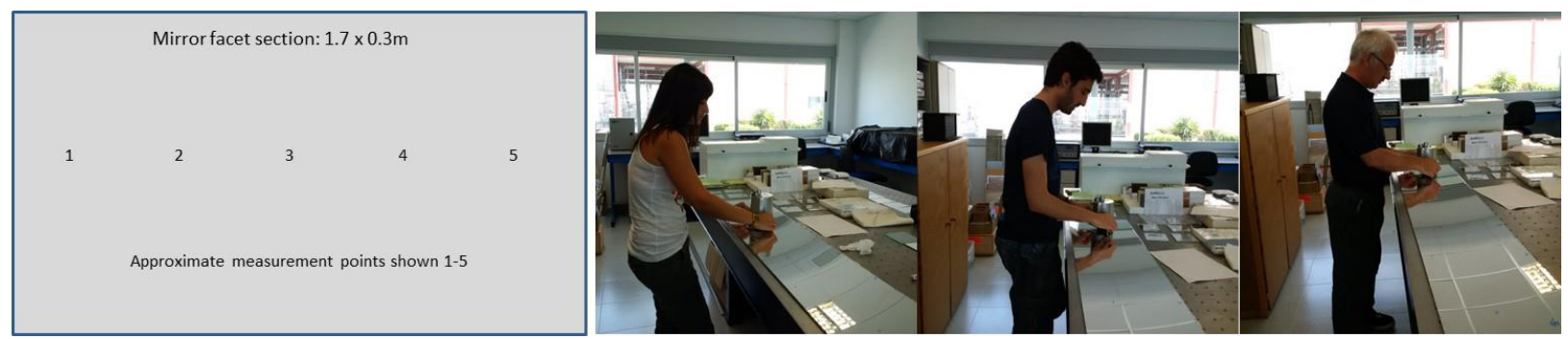

Fig 2. Gage R\&R showing measurement positions and three observers using the D\&S reflectometer.

Each observer took two sets of measurements and the order in which measurements were taken was randomized. It should also be mentioned that the reflectance was measured at a wavelength of $650 \mathrm{~nm}$ using the Condor and $660 \mathrm{~nm}$ using the D\&S instrument. If we assume that the Pettit approximation is true (Pettit, 1977), which is the case for highly specular mirrors such as the facet used in this work, then the ratio of specular reflectance to hemispherical reflectance is wavelength independent. As there is no significant difference between the hemispherical reflectance of solar glass mirrors in the range 650-660 $\mathrm{nm}$ (Montecchi et al., 2015), it may be assumed that there is no significant impact on specular reflectance in this range and the reflectance values from both devices are perfectly comparable.

Before each set of measurements the mirror was cleaned using demineralized water and a soft tissue and blown dry with dry nitrogen. The instruments were calibrated by the observers using each instrument's recommended calibration mirror. The measurements were carried out in less than one hour during which the ambient temperature remained unchanged. In particular, the operating temperature within the Condor remained at $34^{\circ} \mathrm{C}$.

\subsection{Outdoor soiling comparison}


The outdoor experiments were carried out on a PTC test line at CIEMAT-PSA, named the HTF loop (see Fig. 3). This facility was specially designed and erected for testing all types of PTC components (reflectors, receivers, back support structures, and tracking systems). As a testing collector, it is East-West oriented.
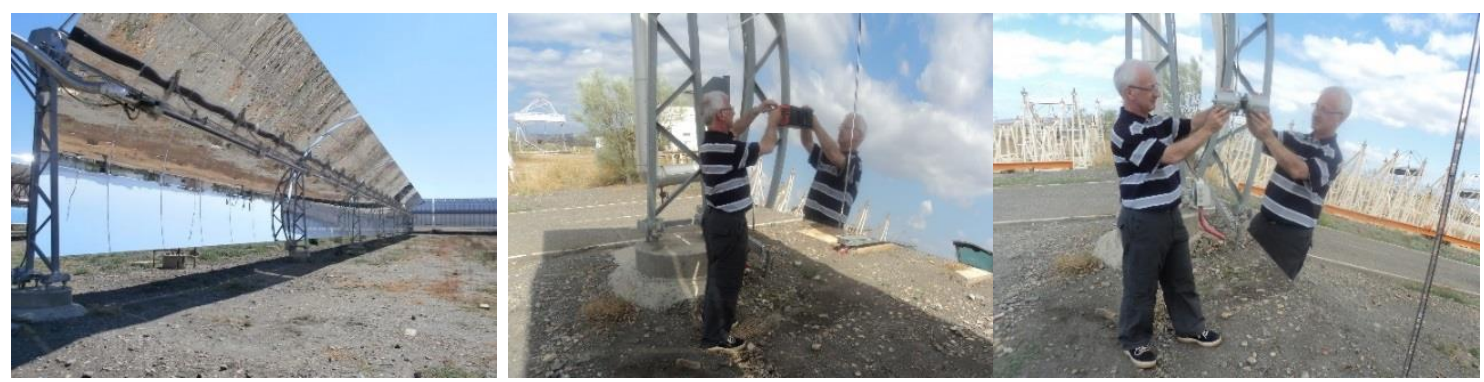

Fig. 3. The PTC line (left) with Condor (center) and D\&S (right) reflectance measurements being taken.

The measurements for the experiments were taken at the lower facets (collector South, module 6, facets F5, F6 and F7 - see Fig. 4) using both the Condor and D\&S reflectometers. Five measurements were taken at each facet (points from P1 to P5 in Fig. 4), in order to collect sufficient information regarding the soiling behavior across the entire facet surface.

The measurements were made immediately after cleaning and subsequently as the mirrors soiled naturally. In total, ten sets of data were taken between the period $20^{\text {th }}$ May to $10^{\text {th }}$ June 2015 . However, a rain-shower on $1^{\text {st }}$ June produced different degrees of dust removal and smearing on the three facets, and provided an interesting and unforeseen split in the data.

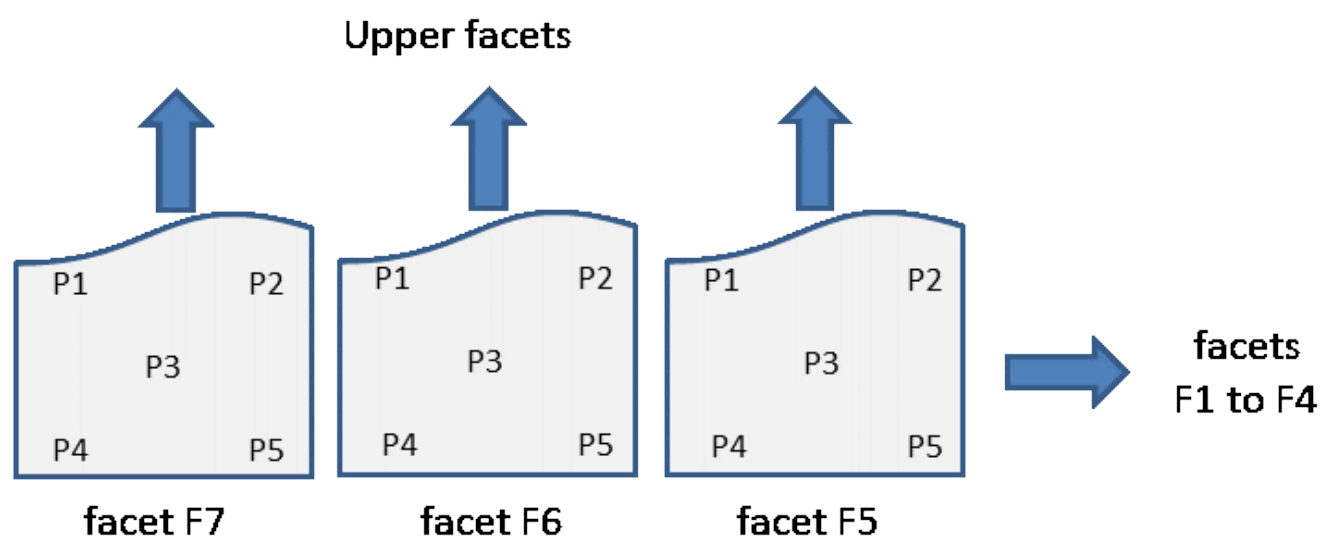

Fig. 4. Schematic of collector showing position of each facet and the five measurement points.

\section{Experimental results}

\subsection{Gage $R \& R$ results}


To assess and compare the capability of both reflectometers, the Gage R\&R study was performed using Minitab ${ }^{\circledR}$ statistical software. The Gage R\&R Study (“crossed") option was selected in order to carry out a more accurate analysis of variance (ANOVA) (which includes both operator and operator-by-part interaction). To be clear, the study is called "crossed" because the same sites are measured by each operator multiple times. The Minitab ${ }^{\circledR}$ outputs are shown in Fig. 5 (D\&S) and Fig. 6 (Condor).

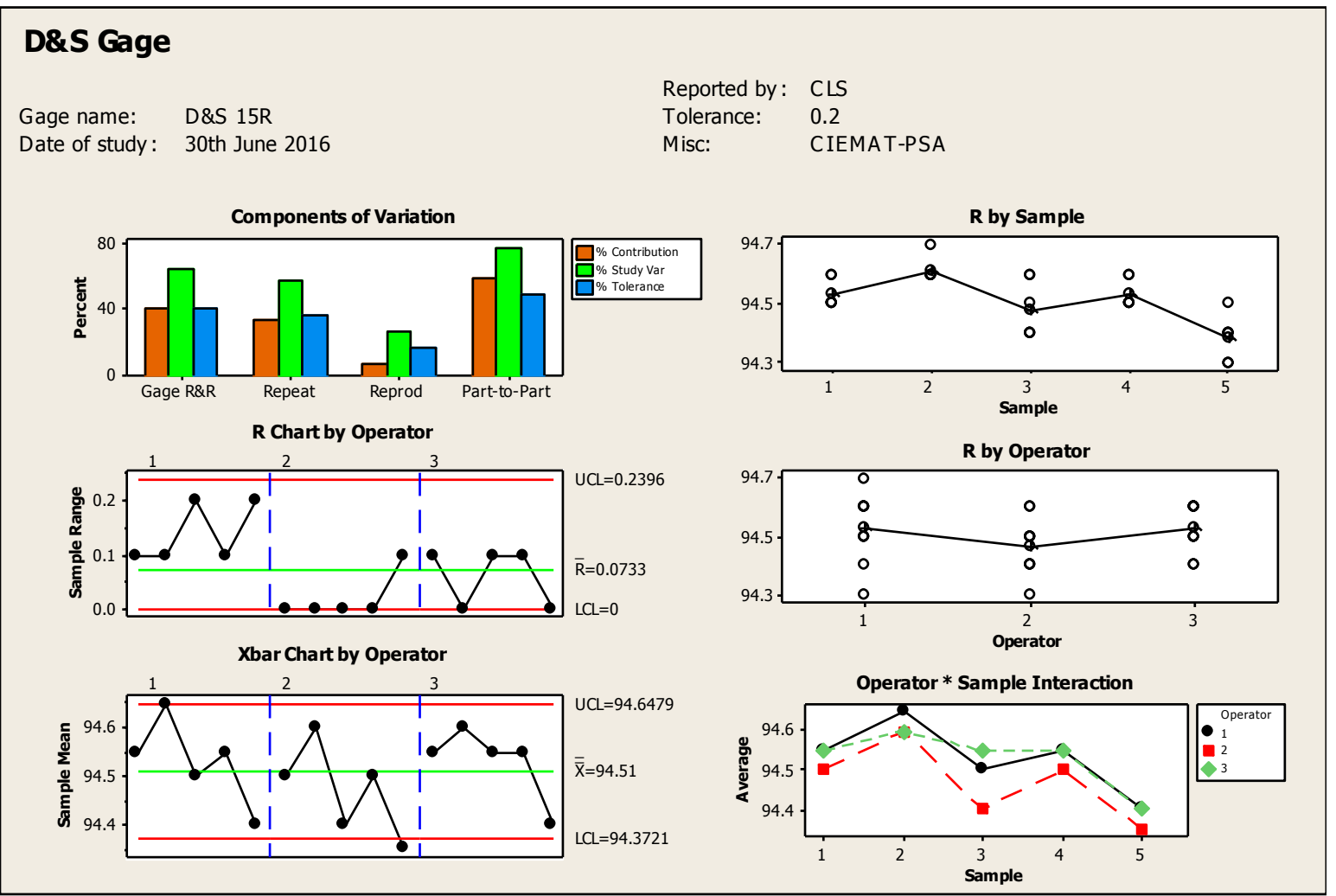

Fig. 5. Gage R\&R results for the D\&S reflectometer. 


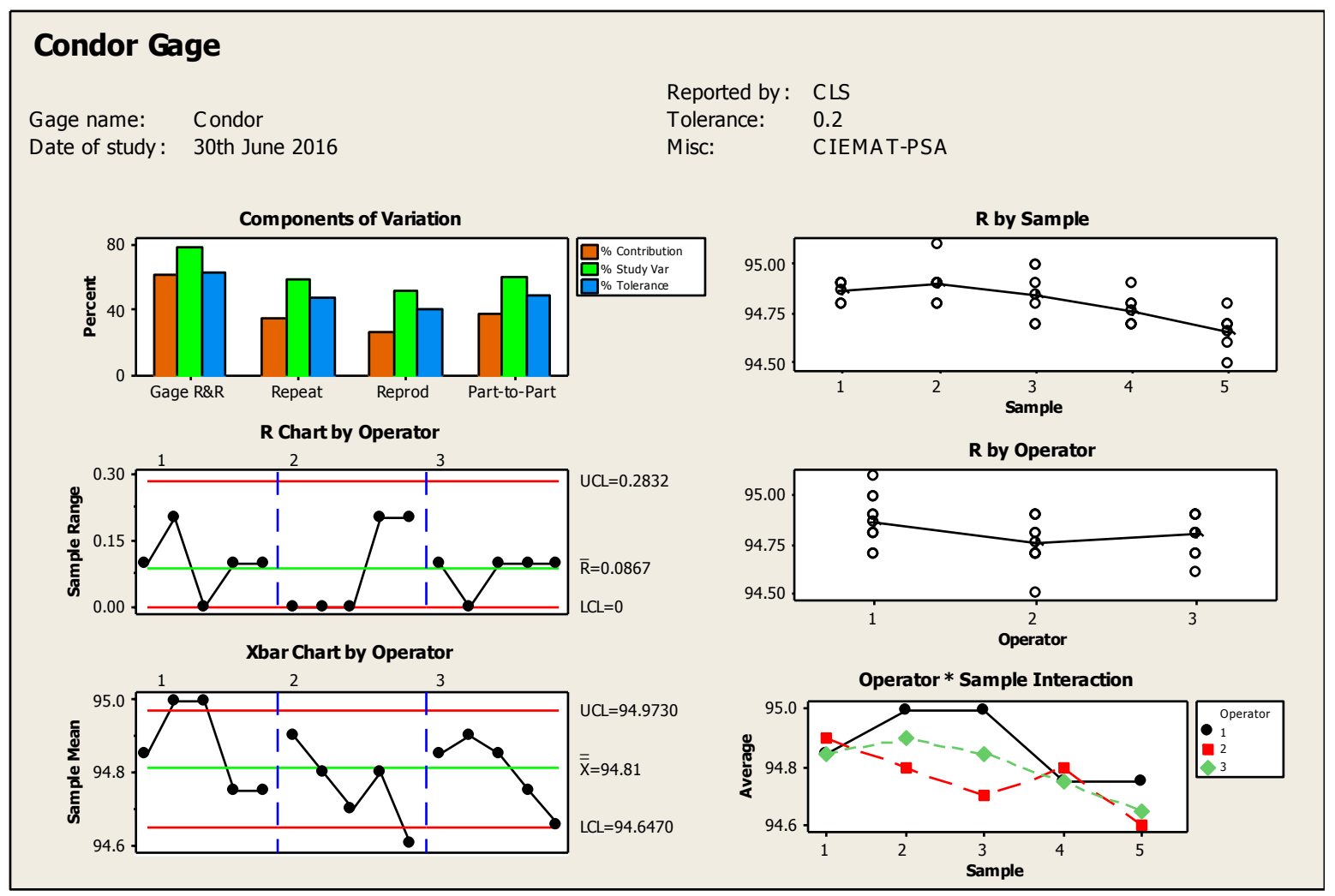

Fig. 6. Gage R\&R results for the Condor reflectometer.

Consider first Fig. 5 (with the detailed statistical output shown in Appendix A), the Gage R\&R study of the D\&S reflectometer. The \% Contribution histograms in the Components of Variation graph show that the gage (D\&S) contributes $40.97 \%$ of the variability, whilst $59.03 \%$ is due to part-to-part (location on the mirror under investigation) variability. Ideally, we would prefer the reflectometer to contribute less to the variability than $40 \%$, but these precise optical measurements require an experienced operator. From the same histograms we can see that the main contribution to the variability in the gage comes from its repeatability, rather than its reproducibility. The \% Study Variation represents the ability of the reflectometer to distinguish between reflectance at different locations (part-to-part differences). At a value of $64.01 \%$ in gage $R \& R$, this percentage is considered to be high (less than $30 \%$ would indicate a good measurement system), indicating that the instrument is not ideal for determining the small differences in reflectance that can occur across such high-quality specular mirrors. The \% Tolerance is defined as Study Variation/Tolerance. In Fig. 5 the contributions to the variability from the gage and the part-to-part variabilities are comparable ( $40.83 \%$ against $49.0 \%$ respectively) for a tolerance of $0.2 \%$ in reflectance. This is a tight tolerance, and at this tolerance the reflectometer is only just capable of discerning differences in parts from its own measurement system variability.

Let us now consider the other graphs in Fig. 5. The Xbar chart should contain out-of-control conditions (above the UCL or below the LCL) if the location-to-location variation is dominant, which is only the case on one occasion for Operator 2 at location point 5. The $R$ (reflectance) Chart by Operator suggests that a special (or assignable) cause may exists for Operator 1, since their readings are slightly higher than both other operators. In fact, Operator 1 is by far the most experienced user of the D\&S 
reflectometer. The D\&S requires an optical adjustment of the beam source to be made in order to maximize the final reading of reflectance. It is likely that this is a skill which improves with practice. Hence Operator 1 is seen to have the greatest range in reflectance values, whereas the less experienced operators 2 and 3 have similar ranges in results and are less likely to obtain the optimum value. This conclusion is confirmed in the $R$ by Operator plot. The $R$ by sample plot is interesting, showing a small reduction in reflectance from left to right across the mirror facet. Finally, the operator*sample interaction plot shows the difference between operators once again, with the largest disagreements appearing to be at locations 2 and 3 on the mirror. On all of the plots, lines are drawn to connect the individual points for clarity. However on the R by Sample and $\mathrm{R}$ by Operator plots the solid lines connect mean values.

The statistical summaries behind these plots are shown in Appendix A. One particular parameter that is of particular relevance to our investigation is the value of $P$ for Operator, which for the D\&S instrument is 0.014 . The parameter $P$ is the probability that the variability in the measurements due to the operator could have occurred by chance alone (owing to random rather than assignable causes). This is extremely low, hence we again conclude that that is a special cause involved, namely the greater skill of Operator 1. Despite the interesting reproducibility result, the overall summary is that the D\&S reflectometer has a larger repeatability issue than reproducibility, and is at the limit of its capability in resolving the very small differences in reflectance across a very high quality specular mirror.

Let us now compare the above analysis with Fig. 6 and the results from the Condor Gage R\&R measurements. The first graph shows that the \% Contribution from the gage (the Condor) is $62.18 \%$ of the total variability with only $37.82 \%$ of the contribution attributable to the location dependent reflectance. This is the reverse of the situation we found with the D\&S reflectometer. This implies that the Condor is less able to distinguish between the small differences in reflectance across a highly specular mirror than the D\&S instrument. The \% Study variation is $78.85 \%$, which is higher than the corresponding D\&S value of 64.01\%, and leads to the same conclusion. The \% Tolerance in Fig. 6 shows that contributions to the variability from the gage and the part-to-part variabilities are no longer comparable (63.4\% against $49.45 \%$ respectively) for a tolerance of $0.2 \%$ in reflectance. Thus, the Gage $R \& R$ study demonstrates the disadvantages of the Condor in the task of discerning small changes in reflectance over a highly specular mirror surface. On this occasion the $R$ chart by Operator does not indicate any special causes in the variability attributable to any of the operators. This is despite the fact that operator 3 is very experienced in using the Condor reflectometer, whereas the other two operators are not. However, one of the great advantages of the Condor is that it requires no adjustment, and no additional skills are likely to be attained with practice. The Xbar Chart by Operator does show that Operator 1 obtains higher readings on average than the other two operators, which is also clearly visible on the $\mathrm{R}$ by Operator plot. There is no obvious explanation for this, other than the possibility that Operator 1 may also be more efficient at cleaning the mirror before taking measurements. In Appendix B we can see that the value of $P$ for Operator, which for the D\&S instrument was $P=0.014$, is now given by $P=0.141$ for the Condor. Unlike the D\&S results we can therefore conclude that the operators do not get significantly different average results when using the Condor. Finally, the Operator*Sample Interaction plot shows the difference between operators once again, with the largest disagreements appearing to be at locations 2 and 3 on the mirror. This was also seen in Figure 5 with the D\&S. It may be that there are local variations in reflectance at those locations, and the operators are not measuring at exactly the same locations on the mirror. To determine this, more results would be needed at those locations. 
The overall summary is that the Condor reflectometer has both repeatability and reproducibility issues, and is also at the limit of its capability in resolving the very small differences in reflectance across a very high quality specular mirror. It is easier to use than the D\&S, does not require additional skills gained through experience, and is more flexible in theory in terms of the curvature and thicknesses of the mirrors it can measure. However, from a gage capability perspective in the context of measuring very small differences in reflectance on highly specular solar mirrors, the D\&S reflectometer is the more capable instrument. Even so, both instruments were able to detect the trend of decreasing value of reflectance from left to right across the sample mirror facet section.

\subsection{Outdoor soiling results}

As outlined in Section 2.3, the outdoor experiments were carried out on the PTC test line at CIEMATPSA called the HTF loop. The raw data points are plotted in Fig. 7(a-d). Each graph shows reflectance against facet location as presented in Fig. 4. Each graph also reports reflectance as measured by one of the two reflectometers for five locations on three separate facets of the collector. The results are shown in four separate plots since we wish to compare the results from the two reflectometers, but also take the opportunity to analyze the results both before (Fig. 7a,7b) and after (Fig. 7c,7d) the rain that fell on June $1^{\text {st }}$, which partially cleaned the collector facets.

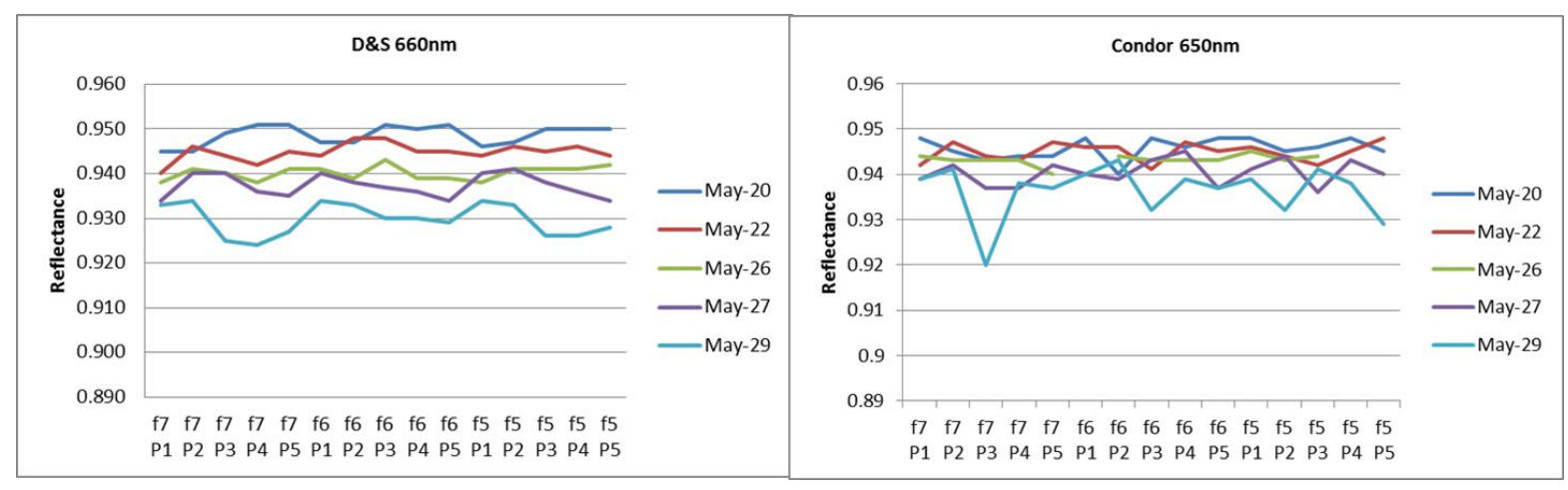

Fig. 7a. Pre-rain measurements; D\&S instrument.

Fig. 7b. Pre-rain measurements; Condor instrument.

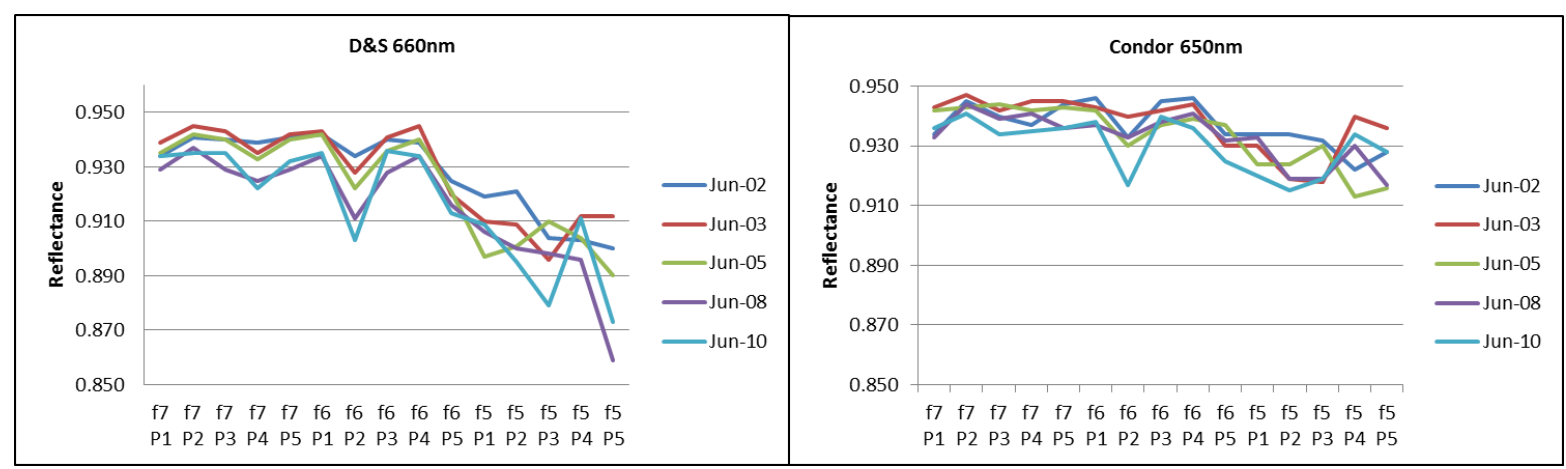

Fig. 7c. Post-rain measurements; D\&S instrument.

Fig. 7d. Post-rain measurements; Condor instrument. 
Comparing Fig. 7a with Fig. $7 \mathrm{~b}$ we can see that the D\&S reflectometer shows a more consistent decrease of specular reflectance with time (and therefore of soiling) than the Condor. The rate of change of reflectance with time is also greater using the D\&S instrument. Both of these observations can be attributed to the much larger acceptance aperture of the Condor, which is unable to resolve small changes in specularity as dust particles begin to soil the mirror surface. The trends are not as obvious after the rain shower (as shown in Fig. 7c and Fig. 7d). The comparison between the two reflectometers is shown more clearly in Fig. 8, where the corresponding measurements from the two reflectometers are plotted against each other.

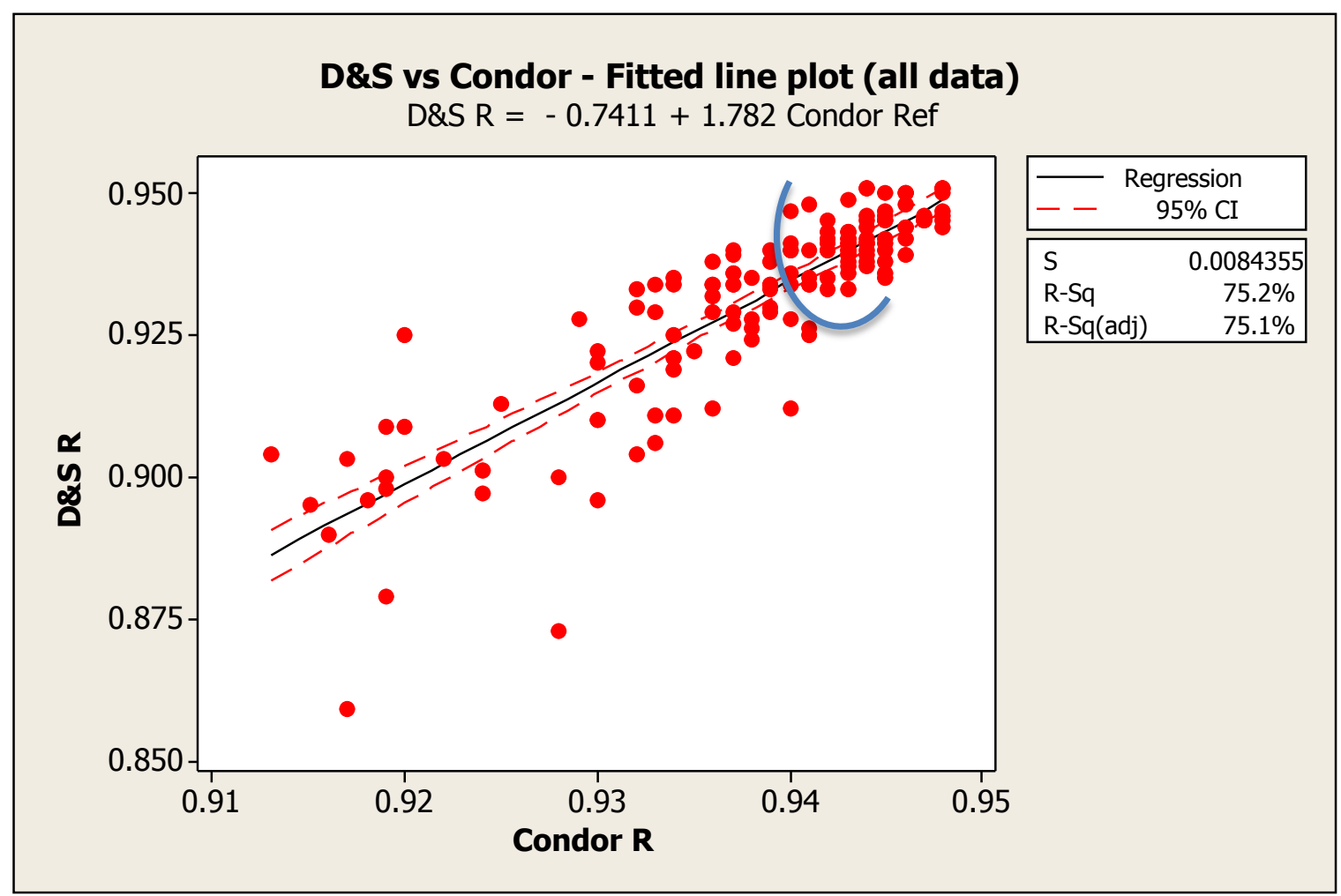

Fig. 8. Fitted Line plot and regression analysis, D\&S and Condor reflectometer comparison.

Here the two sets of readings from the two instruments are fitted with a regression line. The regression equation is " $R(D \& S)=-0.7411+1.782 \cdot R($ Condor $)$ ". With an R-Sq value of $>75 \%$, [R-Sq $-\mathrm{RSq}(\operatorname{adj})]$ $<2 \%$ and $P<0.0005$, the correlation is statistically significant. The regression line has been used to construct Table 2, which compares the predicted differences between the two reflectometer readings in the range $0.91-0.95$ (as measured by the Condor). The Condor measures higher than the D\&S by an average of $1.53 \%$, which compares with an earlier published value of $1.35 \%$ (Salinas et al., 2016).

Table 2

Reflectometer comparison (from regression line).

\begin{tabular}{|c|c|c|c|}
\hline $\begin{array}{c}\text { Reflectance (Condor) } \\
\text { "Condor } R \text { ” }\end{array}$ & $\begin{array}{c}\text { Reflectance (D\&S) } \\
\text { "D\&S } R \text { " }\end{array}$ & $\begin{array}{c}\text { Condor } R- \\
\text { D\&S } R\end{array}$ & $\begin{array}{c}\% \text { Difference } \\
\text { (D\&S } R \text { as base) }\end{array}$ \\
\hline 0.950 & 0.952 & -0.002 & -0.189 \\
\hline
\end{tabular}




\begin{tabular}{|l|l|l|l|}
\hline 0.948 & 0.948 & 0.000 & -0.025 \\
\hline 0.946 & 0.945 & 0.001 & 0.141 \\
\hline 0.944 & 0.941 & 0.003 & 0.307 \\
\hline 0.942 & 0.938 & 0.004 & 0.475 \\
\hline 0.940 & 0.934 & 0.006 & 0.645 \\
\hline 0.938 & 0.930 & 0.008 & 0.815 \\
\hline 0.936 & 0.927 & 0.009 & 0.987 \\
\hline 0.934 & 0.923 & 0.011 & 1.160 \\
\hline 0.932 & 0.920 & 0.012 & 1.335 \\
\hline 0.930 & 0.916 & 0.014 & 1.511 \\
\hline 0.928 & 0.913 & 0.015 & 1.688 \\
\hline 0.926 & 0.909 & 0.017 & 2.047 \\
\hline 0.924 & 0.905 & 0.019 & 2.228 \\
\hline 0.922 & 0.902 & 0.020 & 2.411 \\
\hline 0.920 & 0.898 & 0.022 & 2.596 \\
\hline 0.918 & 0.895 & 0.023 & 2.781 \\
\hline 0.916 & 0.891 & 0.025 & 2.969 \\
\hline 0.914 & 0.888 & 0.026 & 3.158 \\
\hline 0.912 & 0.884 & 0.028 & 3.348 \\
\hline 0.910 & 0.881 & 0.029 & \\
\hline
\end{tabular}

Considering Fig. 8 again, the readings taken before the rain shower (before June $1^{\text {st }}$ ) are all clustered above the blue arc drawn in the top-right corner of the Figure. The readings from June $2^{\text {nd }}$ onwards are all below the blue arc. Despite the regression line still remaining statistically significant it is clear that the rain has created reflectance data pairs that are not as regular as those measured before it. To find the reasons for this, a deeper analysis of the phenomenon is needed. By chance, the collector facets were washed in natural rainfall on June $1^{\text {st }}$, at the mid-point of the experiments to compare the two reflectometers. The rain commenced at $1: 03 \mathrm{pm}$, and partially cleaned the facets which remained at rightangles to the ground throughout the duration of the experiments. The specular reflectance was measured on June $2^{\text {nd }}$ when the facets were again dry, with results shown in Fig. 9a (D\&S) and Fig. 9b (Condor). In these plots, the facets positions have been re-ordered slightly on the graphs so that the $\mathrm{x}$-axis more accurately represents the distance from the end of the collector line. For example, the end of the collector line is given by facet F7 positions 1 and 4 (see Fig. 4). 


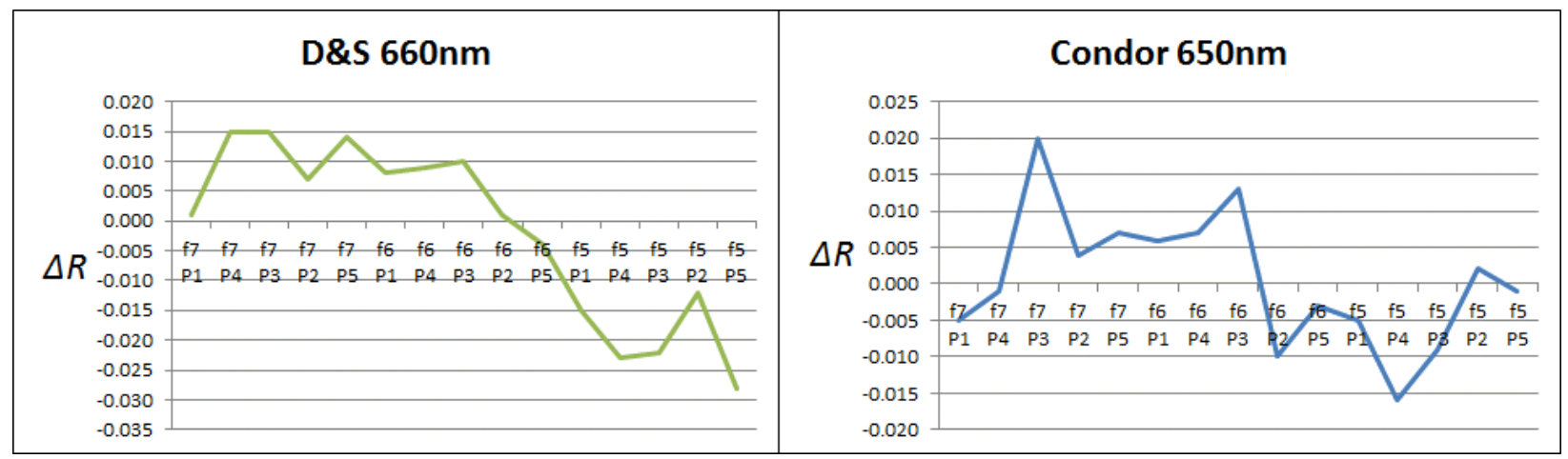

Fig. 9a. Change in specular reflectance after rainfall of June $1^{\text {st}}$; D\&S measurement.

Fig. 9b. Change in specular reflectance after rainfall of June $1^{\text {st }}$; Condor measurement.

In Fig. 9, $\Delta R$ represents the change in specular reflectance between May $29^{\text {th }}$ (prior to the rainfall of June $1^{\text {st}}$ ) and June $2^{\text {nd }}$ (when the facets had dried after the rainfall). A positive value indicates an increase in reflectance over that period whereas a negative value indicates a decrease in reflectance. Considering Fig. 9a we can see that the end facet F7 and most of F6 have experienced an increase in reflectance. Backed up by visual inspection we conclude that the end of the collector line has been cleaned by the rain. This cleaning is only partial, since reflectance has not returned to the values measured at the start of the experiments (see also Fig. 7a, 7c). However the be investigated in future work. As an aside, this inhomogeneity was caused by the position of the collector. During the rain it was in the stow position (aperture plane vertical).

Fig. 9b, shows the same measurements, but taken using the Abengoa Condor reflectometer. The trend is similar to that of the D\&S reflectometer, but there is more variability in the results which makes them harder to interpret. We could reach the same conclusions as those from the D\&S results, but with less certainty. Again we attribute the difference in the results to the difference in acceptance aperture which tends to make the D\&S instrument more capable in resolving small changes in specularity at $660 \mathrm{~nm}$ as the soiling increases, and additional changes in reflectance after inhomogeneous washing like it was the case during this rain event.

The interpretation that the rain has cleaned facet F7 whilst facets F6 and F5 have been partially sheltered from the rain is also supported by the weather data for June $1^{\text {st }}$. According to the data routinely collected at the PSA weather station, rain fell from 13:03 to 13:52 on June $1^{\text {st }}$ (intermittent rain, $\leq 0.11 / \mathrm{m}^{2}$ ). The average wind speed during that time was $6.5 \mathrm{~m} / \mathrm{s}$ and the wind direction during the same period is shown in Fig. 10. Here, wind direction is measured clockwise from North, hence wind directions in the range 236-257 represent a WSW (west-south-westerly) wind. 


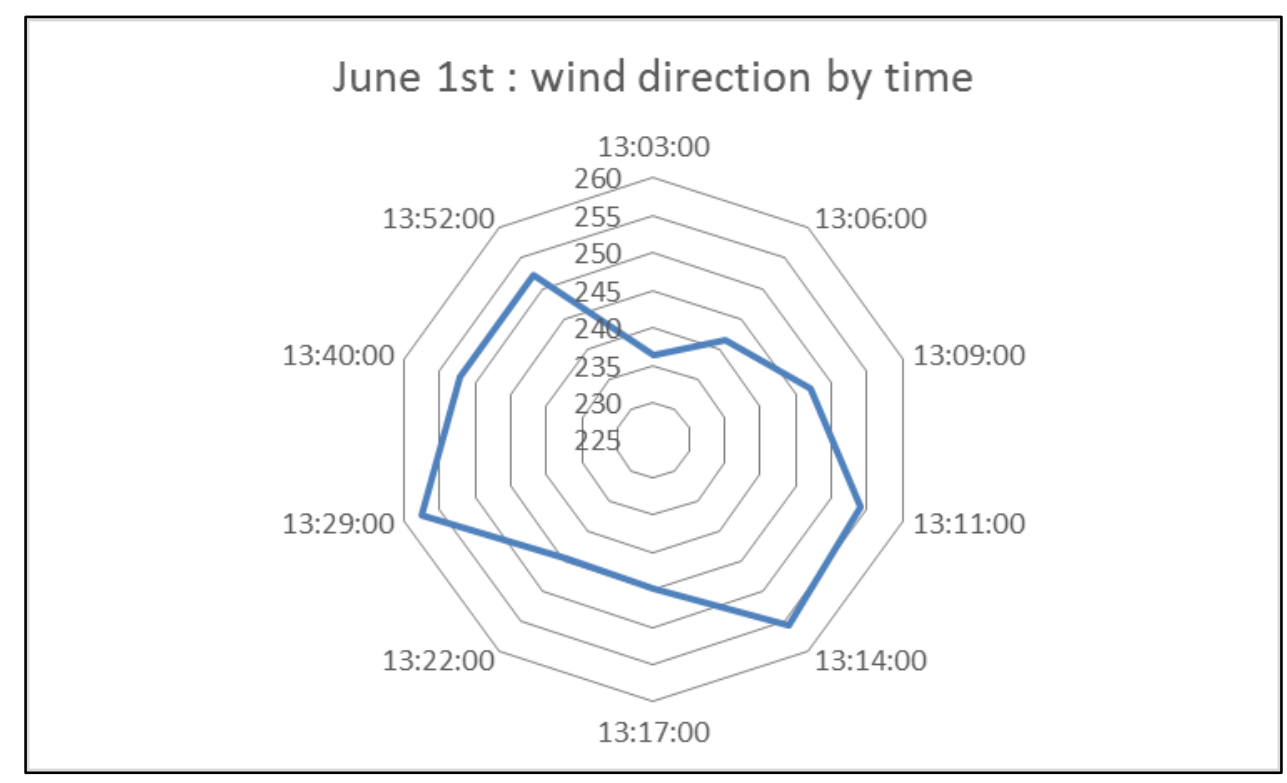

Fig. 10. Wind direction (in degrees clockwise from North) against time - CIEMAT PSA

The collector facets under investigation are aligned E-W, and the wind (and rain) direction relative to the facets is shown in Figure 11. We can see that the end facet F7 is likely to have been preferentially cleaned with the inner facets shaded to some degree.

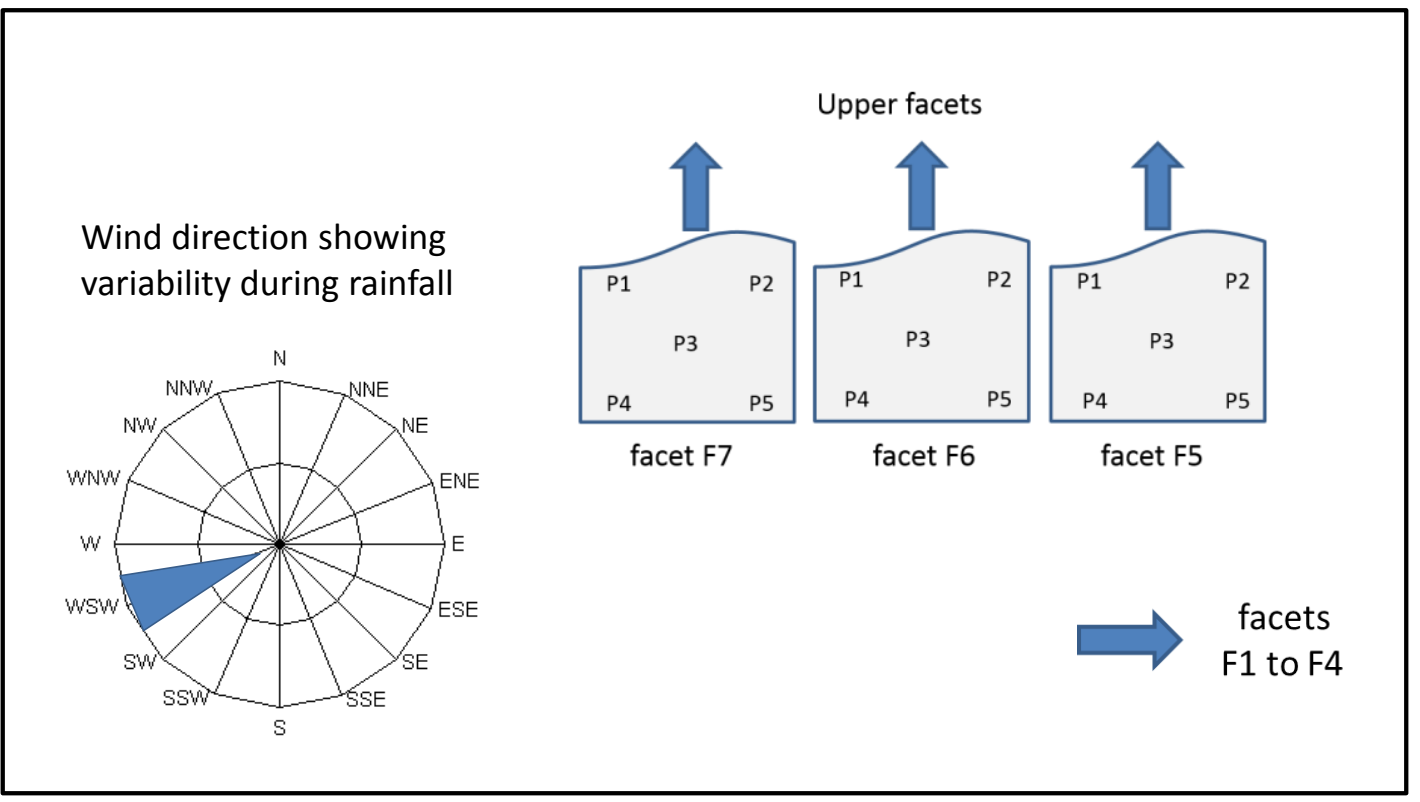

Fig. 11. Wind direction during rainfall event; relative to the E-W collector orientation 
The collectors used for this work did not track the sun, and hence the soiling of the mirrors is not totally representative of a CSP power plant. Also, any conclusions regarding the rate of cleaning will depend significantly on the geographical location and local climate conditions. Nevertheless, it is interesting to consider the effectiveness of the two reflectometers if used for that purpose at this specific location.

At the start of the tests, the average specular reflectance as measured using the D\&S was given by $R_{a v}(D \& S)=0.949$. We can stipulate that cleaning is necessary when the average reflectance has dropped to $95 \%$ of this value, i.e. $R_{a v}(D \& S)=0.902$. From our results, this occurred on June $5^{\text {th }}$, or 16 days after the initial cleaning.

A similar calculation for the Condor reflectometer requires that the reflectance should fall from its initial average value of $R_{a v}($ Condor $)=0.946$ to a value of $R_{a v}($ Condor $)=0.899$. Since this value was not reached during the period of our experiments we can only conclude that the $95 \%$ limit would be reached at $>21$ days. This result again suggests that the higher resolution of the D\&S instrument would be a better indicator of the required frequency of cleaning, assuming that the need for cleaning is determined by the loss of specular reflectance, which is a simplification because financial issues should be also considered.

\section{Conclusions}

This work compares the effectiveness of the two most commonly used reflectometers in CSP solar field reflectance situations. We have carried out a Gage R\&R analysis of the D\&S 15R-USB and the Abengoa Condor SR 6.1 reflectometers. Both instruments are able to measure specular reflectance of solar mirror. However, both instruments are on the limits of their capability in resolving the very small differences in reflectance that are found across clean high-quality and specular reflecting surfaces. To compare the two reflectometers for outdoor use, the impact on reflectance by soiling on solar concentrating silvered-glass mirrors on a CIEMAT-PSA test loop was determined. The Condor instrument contains no moving parts or accessories, is simple to calibrate, easy to use, and provides rapid measurements at six wavelengths across the solar spectrum. Having the capability to measure six wavelengths over a period of a few seconds is a considerable asset, which can outweigh any loss of precision in a single wavelength measurement, depending on the circumstances. Data is also easy to download and a solar-weighted spectrum can also be obtained. The D\&S portable specular reflectometer requires a more experienced person to calibrate and operate the instrument, especially in an outdoor environment. Nevertheless, the results of this work demonstrate that the D\&S provides superior resolution when tasked with distinguishing between the small changes in specular reflectance that occur when a solar collector is naturally soiled. As natural rainfall occurred during the tests we were also able to observe the partial cleaning of facets by raindrops. Both instruments were able to distinguish between facets which had been cleaned and only partially cleaned, although the clearest interpretations were once again obtainable from the D\&S results. The Condor routinely measures higher reflectance values than the D\&S instrument owing to its larger acceptance aperture. This is less apparent on highly specular and clean surfaces, but the difference in reflectance becomes more significant as the surface soiling increases. In this work the average percentage difference average between the two instruments was $1.5 \%$ (D\&S instrument as base) over the reflectance range $0.91-0.95$. We conclude that both instruments have their place in measuring the specular reflectance of solar collector facets in the solar fields of arid and dusty regions, depending on the 
experience of the user, the time available, and the resolution required. Both instruments are capable of determining soiling levels on solar mirrors and can be used to determine the need for mirror cleaning.

\section{Acknowledgements}

Financial support by the Access to Research Infrastructures activity in the $7^{\text {th }}$ Framework Program of the EU (SFERA 2 Grant Agreement n. 312643) is gratefully acknowledged.

\section{References}

Bethea, R., Barriger, M., Williams, P., Chin, S., 1981. Environmental effects on solar concentrator mirrors. Sol. Energy 27 (6), 497-511. Doi: 10.1016/0038-092X(81)90045-1.

Bouaddi, S., Ihlal, A., Fernández-García, A., 2015. Soiled CSP solar reflectors modelling using dynamic linear models. Sol. Energy 122, 847-863. doi: 10.1016/j.solener.2015.09.04.4.

Crawford, J.S., Stewart, J., Pérez-Ullivarri, J.A., 2012. A comparison of three portable reflectometers for use in operations and maintenance of CSP plants. In: Proceedings of SolarPACES Conference, Marrakech, Morocco, 2012.

DiGrazia, M., Gee, R. Jorgensen, G., 2009. ReflecTech mirror film attributes and durability for CSP application. In: American Society of Mechanical Engineers (ed.), 5th International Conference on Energy Sustainability, 1, 19-23, San Francisco, California, USA.

Fernández-García, A., Álvarez-Rodrigo, L., Martínez-Arcos, L., Aguiar. R., Márquez-Payés, J.M., 2014a. Study of different cleaning methods for solar reflectors used in CSP plants. Energy Procedia 49, 8089. doi: 10.1016/j.egypro.2014.03.009.

Fernández-García. A., Cantos-Soto, M.E., Röger, M., Wieckert, C., Hutter, C., Martínez-Arcos, L., 2014b. Durability of solar reflector materials for secondary concentrators used in CSP systems. Sol. Energy Mater. Sol. Cells. 130, 51-63. doi: 10.1016/j.solmat.2014.06.043.

Fernández-García, A., Sutter, F., Martínez-Arcos, L., Sansom, C., Wolfertstetter, F., Delord, C., 2017. Equipment and methods for measuring reflectance of concentrating solar reflector materials. Submitted to Sol. Energy Mater. Sol. Cells.

Ho, C., Sment, J., Yuan, J., Sims, C., 2013. Evaluation of a reflective polymer film for heliostats. Sol. Energy 95, 229-236. Doi: 10.1016/j.solener.2013.06.015.

Martinez, N., Navio, R., Heras, C., Salinas, I., Mainar, M., 2012. A New Portable Specular Reflectometer, Condor: Description, laboratory and field tests. Proceedings of SolarPACES Conference, Marrakech, Morocco, 2012.

Meyen, S., Fernández-García, A., Kennedy, C., Lüpfert, E., 2010. Standardization of solar mirror reflectance measurements - Round Robin Test. In: Proceedings of SolarPACES Conference. Perpignan (France). France, 2010.

Montecchi, M., Delord, C., Raccurt, O., Disdier, A., Sallaberry, F., García de Jalón, A., FernándezGarcía, A., Meyen, S., Happich, C., Heimsath, A., Platzer, W., 2015. Hemispherical Reflectance Results of the SolarPACES Reflectance Round Robin. Energy Procedia; 69: 1904-1910. Doi: 10.1016/j.egypro.2015.03.174.

Pettit, R.B., 1982. Characterizing Solar Mirror Materials Using Portable Reflectometer. Tech. rep. No. SAND82-1714. Sandia National Labs., Albuquerque:, NM (USA), 1981.

Pettit, R.B., 1977. Characterization of the reflected beam profile of solar mirror materials. Sol. Energy 19(6), 733-741.

Pitz-Paal, R., Dersch, J., Milow, B., Téllez, F., Ferriere, A., Langnickel, U., et al., 2007. Development Steps for Parabolic Trough Solar Power Technologies With Maximum Impact on Cost Reduction. J. Sol Energy Eng., 129, 371-377. doi: 10.1115/1.2769697. 
Salinas, I., Heras, C., Alcaniz, C., Izquierdo, D., Martinez, N., Alonso, R., 2016. Portable Solar Spectrum Reflectometer for planar and parabolic mirrors in solar thermal energy plants. Sol. Energy 135, 446454. Doi: 10.1016/j.solener.2016.06.010.

Sutter, F., Ziegler, S., Schmücker, M., Heller, P., Pitz-Paal, R., 2012. Modelling of optical durability of enhanced Aluminium solar reflectors. Sol. Energy Mater. Sol. Cells, 107, 37-45. doi: 10.1016/j.solmat.2012.07.027.

Tahboub, Z.M., Dahleh, B., Goebel, O., 2012. Solar Mirrors Soiling Campaign - Abu Dhabi.. In: Proceedings of SolarPACES Conference, Marrakech, Morocco, 2012.

\section{Appendix A: Mintab output (D\&S 15R)}

\section{Gage R\&R Study - ANOVA Method}

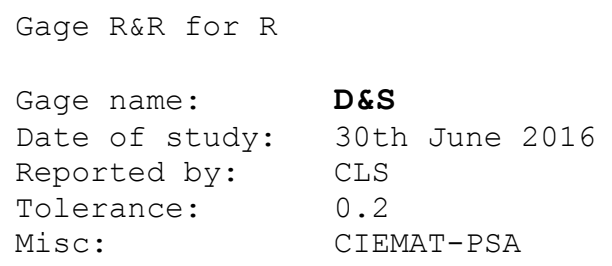

\section{Two-Way ANOVA Table With Interaction}

$\begin{array}{lrrrrr}\text { Source } & \text { DF } & \text { SS } & \text { MS } & \text { F } & \text { P } \\ \text { Sample } & 4 & 0.175333 & 0.0438333 & 27.6842 & 0.000 \\ \text { Operator } & 2 & 0.024000 & 0.0120000 & 7.5789 & 0.014 \\ \text { Sample * Operator } & 8 & 0.012667 & 0.0015833 & 0.3167 & 0.947 \\ \text { Repeatability } & 15 & 0.075000 & 0.0050000 & & \\ \text { Total } & 29 & 0.287000 & & & \end{array}$

\section{Gage R\&R}

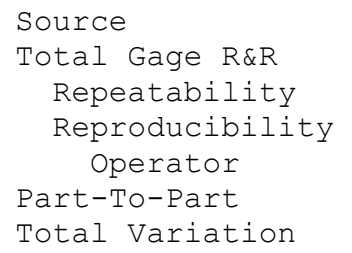

VarComp
0.0046304
0.0038116
0.0008188
0.0008188
0.0066703
0.0113007

ocontribution
(of VarComp)
40.97
33.73
7.25
7.25
59.03
100.00

StdDev (SD)
0.068047
0.061738
0.028615
0.028615
0.081672
0.106305

Study Var
$(6 \star S D)$
0.408284
0.370429
0.171692
0.171692
0.490031
0.637829
oStudy Var oTolerance ( $\% \mathrm{SV}) \quad(\mathrm{SV} / \mathrm{Toler})$
$64.01 \quad 40.83$
$58.08 \quad 37.04$
$26.92 \quad 17.17$
$26.92 \quad 17.17$
$76.83 \quad 49.00$
$100.00 \quad 63.78$




\title{
Appendix B: Minitab output (Abengoa Condor) \\ Gage R\&R Study - ANOVA Method
}

\author{
Gage $R \& R$ for $R$ \\ Gage name: Condor \\ Date of study: 30th June 2016 \\ Reported by: CLS \\ Tolerance: $\quad 0.2$ \\ Misc: CIEMAT-PSA
}

\section{Two-Way ANOVA Table With Interaction}

$\begin{array}{lrrrrr}\text { Source } & \text { DF } & \text { SS } & \text { MS } & \text { F } & \text { P } \\ \text { Sample } & 4 & 0.212 & 0.0530000 & 4.32653 & 0.037 \\ \text { Operator } & 2 & 0.062 & 0.0310000 & 2.53061 & 0.141 \\ \text { Sample * Operator } & 8 & 0.098 & 0.0122500 & 1.93421 & 0.129 \\ \text { Repeatability } & 15 & 0.095 & 0.0063333 & & \\ \text { Total } & 29 & 0.467 & & & \end{array}$

\section{Gage R\&R}

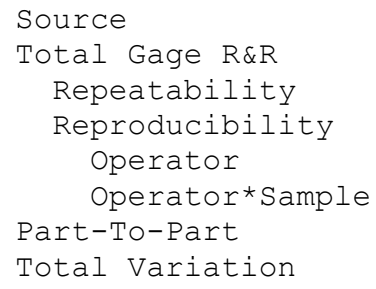

$\begin{array}{rr}\text { VarComp } & \begin{array}{r}\text { oContribution } \\ \text { (of VarComp) }\end{array} \\ 0.0111667 & 62.18 \\ 0.0063333 & 35.27 \\ 0.0048333 & 26.91 \\ 0.0018750 & 10.44 \\ 0.0029583 & 16.47 \\ 0.0067917 & 37.82 \\ 0.0179583 & 100.00\end{array}$

StdDev (SD)

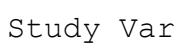

○Study Var

( $\% \mathrm{SV}$ )

78.85

59.39

51.88

32.31

40.59

61.50
oTolerance

(SV/Toler)

63.40

47.75

41.71

25.98

32.63

49.45 
2017-06-29

\section{Reflectometer comparison for}

\section{assessment of back-silvered glass solar mirrors}

Sansom, Christopher L.

Elsevier

Christopher Sansom, Aránzazu Fernández-García, Peter King, Florian Sutter, Alejandro Garcia Segura, Reflectometer comparison for assessment of back-silvered glass solar mirrors, Solar Energy, Volume 155, October 2017, Pages 496-505

http://dx.doi.org/10.1016/j.solener.2017.06.053

Downloaded from Cranfield Library Services E-Repository 